\section{CALCIUM SUPPLEMENTATION}

\section{Results may not be generalisable}

Bolland et al showed an increased risk of vascular events, particularly myocardial infarction, in healthy postmenopausal women receiving calcium supplements. ${ }^{12}$ We recently completed a similar study with a primary skeletal end point. ${ }^{3}$ We queried our database about the principal adverse events reported by Bolland et al.

We followed up 1179 women for four years, similar to the 1471 women followed up by Bolland et al. The calcium supplement dosage was $1400-1500 \mathrm{mg} /$ day, nearly $50 \%$ higher than in Bolland et al, and principally with the same product. We recorded adverse events at six monthly intervals, verified them with the participant's personal physician, and entered in the database using the corresponding ICD-9 code.

Our study had three treatment arms: a double placebo, calcium plus vitamin D, and calcium and a vitamin $\mathrm{D}$ placebo. The total number treated with calcium (with or without additional vitamin D) was 892 , and the person years of exposure to calcium was 3568 , almost identical to the figure in Bolland et al (3660).

The vascular event rate across all groups was 5.3/1000 persons/year, less than half the rate of Bolland et al (12.2/1000). This difference may be because the participants in the study of Bolland et al were on average seven years older. We found no excess occurrence of myocardial infarction or other vascular events in either calcium treatment group compared with

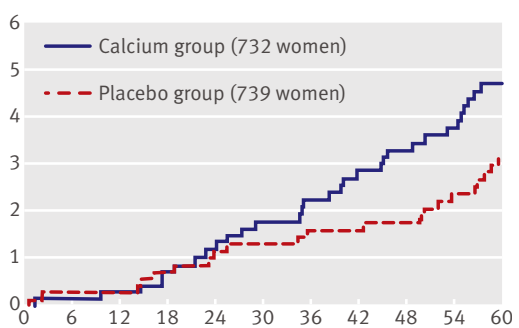

Time to first myocardial infarction (months)

Bolland etal. BMJ 2008;336:262-6

Kaplan-Meier survival plot showing proportion of healthy postmenopausal women with myocardial infarction by treatment group, including self reported events and those from national database of hospital admissions and review of death certificates placebo, despite the higher calcium supplement dose. When the two calcium treatment groups were combined the vascular event rate is $4.76 / 1000$ persons/year, the rate in the placebo group being 6.94 events/1000 persons/year. This difference, while not reaching significance, is in a direction opposite to that found by Bolland et al.

We conclude that the excess of events found by Bolland et al was either a chance occurrence or at least not generalisable to other populations.

Joan M Lappe professor of nursing and medicine jmlappe@creighton.edu

Robert P Heaney John A Creighton university professor, professor of medicine, Creighton University, Omaha, NE 68178, USA

Competing interests: None declared.

1 Bolland MJ, Barber PS, Doughty RN, Mason B, Horne A, Ames $R$, et al. Vascular events in healthy older women receiving calcium supplementation: randomised controlled trial. BMJ 2008:336:262-6. (2 February.)

2 Jackson RD, LaCroix AZ, Gass M, Wallace RB, et al. Calcium plus vitamin D supplementation and risk of fractures. N Engl/ Med 2006;354:669-83.

3 Lappe JM, Davies KM, Travers-Gustafson D, Heaney RP. Vitamin D status in a rural postmenopausal female population. / Am Coll Nutr 2006;25:395-402.

4 Lappe JM, Travers-Gustafson D, Davies KM, Recker RR, Heaney RP. Vitamin D and calcium supplementation reduces cancer risk. Am I Clin Nutr 2007;85:1586-91.

\section{Some issues on outcomes}

The article by Bolland et al was reviewed at our public health department's monthly journal club. ${ }^{1}$ This raised some issues concerning the outcomes used, the method of allocation of the women, and the presented results.

The use of a composite end point (myocardial infarction, stroke, or sudden death) creates difficulties in determining the real impact of calcium supplementation on the relative risk of myocardial infarction. These three outcomes seem to have been combined to create $a$ significant $P$ value.

The allocation of patients to the intervention or placebo groups explained in the original study was based on a minimisation algorithm that did not take into consideration relevant risk factors for cardiovascular disease, such as smoking and use of hormone replacement. ${ }^{2}$ This resulted in groups unbalanced for confounders, which could have an impact on the results.

Smoking was not taken into consideration in the Poisson regression analysis models when examining confounders.

It would have been helpful to have had the results stratified in each intervention arm when looking at specific groups such as smokers, history of smoking, or non-smokers. This would aid clinical decision making.

The "What this study adds" box says that calcium supplementation showed increased rates of myocardial infarction. This statement is based on non-significant findings. This advice is premature. It would have been wiser to wait until the article was debated before conclusions were drawn.

Jinelle N Ramlackhansingh specialist registrar public health, Manchester Primary Care Trust, Manchester M23 9LT jinelle.ramlackhansingh@manchester.nhs.uk Competing interests: None declared.

1 Bolland MJ, Barber PS, Doughty RN, Mason B, Horne A, Ames $R$, et al. Vascular events in healthy older women receiving calcium supplementation: randomised controlled trial. BMJ 2008;336:262-6. (2 February.)

2 Reid IR, Mason B, Horne A. Effects of calcium supplementation on serum lipid concentrations in normal older women: a randomized control trial. $A m$ J Med 2002;112:343-7.

\section{Confounders were ignored}

Bolland et al did not control for vitamin D concentrations during their study but said only that the women with serum 25-hydroxyvitamin D concentrations below 25 $\mathrm{nmol} / \mathrm{I}$ were excluded. ${ }^{1}$ This implies that serum concentrations of vitamin D were not monitored during the study. This is important because, according to the results of the Framingham offspring study, low serum concentrations of vitamin D are strictly associated with an increase in vascular risk ${ }^{2}$ and may impair calcium absorption. ${ }^{2}$

Two important confounding factors are not controlled for-consumption of non-steroidal anti-inflammatory drugs and analgesics and previous hormone replacement therapy. These two potent confounders may completely reverse the results and also interact with each other on cardiovascular risk. ${ }^{3-5}$

To consider the self reported events separately from those unreported but taken from the national database of hospital admissions is surprising. When self reported and unreported events are considered together the differences between calcium and placebo group no longer reach significance. This is the study result: the analysis of self reported events alone looks like window dressing.

Luca Puccetti president, Promed Galileo Medical Society, Pisa 56011, Italy lucpucce@promedgalileo.org 
Competing interests: None declared.

1 Bolland MJ, Barber PS, Doughty RN, Mason B, Horne A, Ames R, et al. Vascular events in healthy older women receiving calcium supplementation: randomised controlled trial. BMJ 2008;336:262-6. (2 February.)

2 Wang TJ, Pencina MJ, Booth SL, et al. Vitamin $D$ deficiency and risk of cardiovascular disease. Circulation 2008. doi 10.1161/ circulationaha.107.706127

3 García Rodríguez LA, Egan K, FitzGerald GA Traditional nonsteroidal anti-inflammatory drugs and postmenopausal hormone therapy: a drug-drug interaction? PLoS Med 2007;4(5):e157.10.1371/ journal.pmed.0040157

4 Cannon CP, Curtis SP, FitzGerald GA, Krum H, Kaur A, Bolognese JA. Cardiovascular outcomes with etoricoxib and diclofenac in patients with osteoarthritis and rheumatoid arthritis in the multinational etoricoxib and diclofenac arthritis long-term (MEDAL) programme: a randomised comparison. Lancet 2006;368:1771-81.

5 Bresalier RS, Sandler RS, Quan H, JA, Oxenius B, Horgan K. Cardiovascular events associated with rofecoxib in a colorectal adenoma chemoprevention trial. NEngl/ Med 2005;352:1092-102.

\section{Data were misrepresented}

The "What this study adds" box accompanying the article by Bolland et al misrepresents the study data. ${ }^{1}$ The first bullet says that healthy older women randomised to calcium supplementation showed increased rates of myocardial infarction. Although the data show that women reported more events, analysis of New Zealand hospital records erased any significant difference in myocardial infarction rates between the calcium and placebo groups. The bulleted statement is not evidence based: the adjudicated results showed no significant increase in cardiovascular end points among women taking calcium. The authors characterised the between-group differences in event rates for myocardial infarction and the composite end point as being of "borderline significance." It cannot be concluded that the women showed "increased rates of myocardial infarction," because a "borderline" P value of 0.058 still means the events could occur by chance.

In addition, the authors' statements in the body of the article do not fully support the conclusion they present in the abstract. In their discussion, the authors say that the study does not unequivocally show an adverse cardiovascular effect of calcium. The double negative of "not unequivocally" should simply say "not": it is a leap to suggest that an adverse effect may occur when the data show no statistical difference between groups. Although the authors go on to note that the present data do not permit definitive conclusions to be reached regarding calcium and cardiovascular events, they highlight "upward trends in cardiovascular event rates" and a "potentially detrimental effect" of calcium supplementation in the abstract's conclusion.

Many people, both clinicians and laypeople, might read only the abstract of this paper. It is therefore unfortunate that your peer review process allowed a stronger statement than the data support. An "upward trend" does not connote statistical significance, so no comment can be made about a detrimental effect of calcium.

Wendy S Biggs associate editor, Journal Watch for Women's Health, Midland Family Medicine Residency, 4005 Orchard Drive, Midland, MI 48670, USA wendy.biggs@midmichigan.org

Competing interests: None declared.

1 Bolland MJ, Barber PS, Doughty RN, Mason B, Horne A, Ames R, et al. Vascular events in healthy older women receiving calcium supplementation: randomised controlled trial. BMJ 2008;336:262-6. (2 February.)

\section{Authors' reply}

Although it is reassuring that Lappe and Heaney did not observe an increase in vascular event rate in subjects randomised to calcium, the small number of events means that this finding should be interpreted with caution. These data will be an important addition to a future meta-analysis.

Other correspondents raise methodological issues. In our article vascular events were clearly specified in the original protocol for this study as secondary events, the hypothesis being one of benefit. The original protocol did not make provision for adjudication of events, neither did it provide for searching of the national database of hospital admissions. Therefore, the originally specified data are those provided in table 2 , which clearly show significant effects of calcium supplementation on the risk of myocardial infarction. The data in tables 3 and 4 provide further scrutiny of the primary data. There is still a statistically significant effect of calcium supplementation on vascular end points in the most conservative dataset, provided in table 4.

We were appropriately conservative in interpreting these data. In general, multiple statistical tests are not adjusted for when assessing adverse events to maximise sensitivity for such negative outcomes. Adjustment for multiple testing is even less appropriate in the current context because the adverse effects studied were pre-specified in the original protocol. The two groups in this study were well balanced with respect to cardiovascular risk factors, $P$ values in table 1 ranging from 0.22 to 0.99 . Previous use of hormone replacement was not different between treatment arms (calcium 8\%, placebo $6 \% ; P=0.13)$.

We have presented important, unexpected findings from the secondary analysis of a carefully conducted, randomised controlled trial. They do not definitively establish that calcium supplementation increases vascular events, but they mandate that this possibility is further investigated as a matter of urgency. lan R Reid professor i.reid@auckland.ac.nz

Mark J Bolland research fellow

Gregory D Gamble research fellow

Andrew Grey associate professor, Department of Medicine, Faculty of Medical and Health Sciences, University of Auckland, Private Bag 92019, Auckland, New Zealand Competing interests: IRR has received research support from and acted as a consultant for Fonterra and Mission Pharmacal

\section{DOES COT DEATH STILL EXIST?}

\section{SIDS is not a disease entity}

The sudden infant death syndrome (SIDS) is not a disease entity. ${ }^{1}$ It is a description of an outcome, a term used to acknowledge a failure to make a diagnosis. The value of the term is that it informs us that no blame is apportioned to the carer. The weakness is that it implies that we understand more than we do. The new term SUDI, or sudden unexpected death in infancy, is unfortunate in that it would have been better if the $U$ stood for "unexplained" rather than "unexpected."

It is important to understand that while parents are usually blameless for the death, they may still be partly responsible. For example, a whole generation of parents laid their babies face down in the cot, believing that they were doing the best. If the parents have contributed to the cause of death we do them a disservice by not saying so.

We know the major risk factors that predispose to cot deaths. These do not strictly cause the death but make it more probable. We could do more to understand these triggers and the mode of death.

A cot death is almost never observed, which suggests that, had appropriate action been taken, the death would have been avoided. From time to time paediatricians see babies who seem to be on the point of death. Some have respiratory infections. They perk up with oxygen, and then seem only to have minor illnesses, hypoxia causing a vicious cycle of under breathing. We see similar recoveries in some babies with gastroenteritis when given intravenous fluids. If these babies had been unobserved at night and had died, I doubt that the pathologist would have recognised the

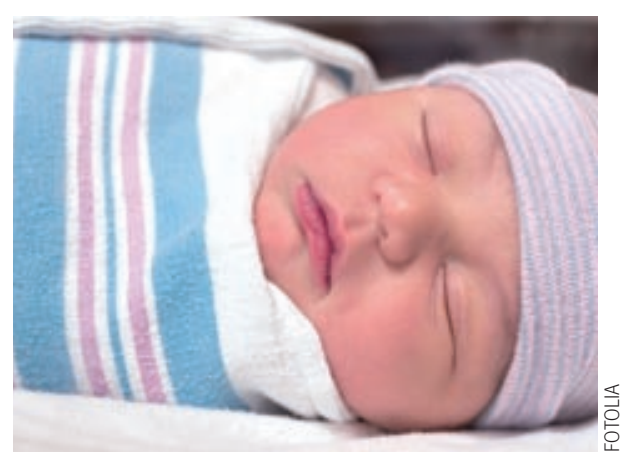


severity of illness that these seemingly minor

infections had induced.

The Care of the Next Infant scheme could devise a comprehensive surveillance of infants at risk that included loop video recording, heart rate monitoring, perhaps other monitoring and an alarm that would both alert the parent and also provide a record of the event so that we might both avoid the death and better understand the process.

Leonard H P Williams consultant paediatrician, Bassetlaw District General Hospital, Worksop S81 OBD

leonard.williams@dbh.nhs.uk

Competing interests: None declared.

1 Gornall J. Does cot death still exist? BMJ 2008;336:302-4. (9 February.)

\section{BENIGN PROSTATIC HYPERPLASIA}

\section{The term BPH is misused}

Drug companies market drugs for BPH (benign prostatic hyperplasia). However, this is a misuse of the term, which all dictionaries define as a histological term and not related to gross anatomical change. It is therefore disappointing that the $B M J$ has commissioned review articles on $\mathrm{BPH} .{ }^{1}$ Several important organisations have accepted the arguments presented in the $B M J$ in 1994, that the term LUTS (lower urinary tract symptoms) should be used rather than "prostatism," and now "storage" and "voiding" symptoms are the preferred terms to "irritative" and "obstructive" symptoms. ${ }^{2-5}$ However, these organisations also supported the proposal for the proper use of the terms BPH (histology), BPE (enlargement), and BPO (obstruction). ${ }^{5}$

Using the correct terminology (BPH, BPE, $\mathrm{BPO}$ ) is likely to protect men from inappropriate treatment and help ensure that care is focused on the cause of their LUTS.

All men have prostates, and if they live long enough they will get histological $\mathrm{BPH}$ : more than $50 \%$ of men aged 50 and $80 \%$ of men older than 70 . However, only a quarter of those with $\mathrm{BPH}$ will get $\mathrm{BPO}$. The gradual development of either $\mathrm{BPH}$ or $\mathrm{BPE}$, without obstruction, seems highly unlikely to cause bothersome LUTS. Wilt and N'Dow mention the causes of LUTS other than prostatic obstruction, but the emphasis is on the prostate. ${ }^{1}$ Unless clinicians appreciate the increasing prevalence of overactive bladder and nocturnal polyuria, men are unlikely to get the help they need when they present with symptoms that affect their quality of life. Paul Abrams professor of urology, Bristol Urological Institute, Southmead Hospital, Bristol BS10 5NB paul_abrams@bui.ac.uk

Competing interests: PA is or has been a consultant, lecturer, investigator and/or the recipient of educational grants from companies marketing products for the treatment of prostatic obstruction, overactive bladder, and nocturia.

1 Wilt TJ, N'Dow J. Benign prostatic hyperplasia. Part 1-Diagnosis. BMJ 2008;336:146-9. (19 January.) 2 Abrams P, Cardozo L, Fall M, Griffiths D, Rosier P,
Ulmsten U, et al. The standardisation of terminology of lower urinary tract function: report from the standardisation sub-committee of the International Continence Society. Neurourol Urodyn 2002;21:167-78.

3 Male lower urinary tract dysfunction: evaluation and management. In: McConnell J, Abrams P, Denis L, Khoury S, Roehrborn C, eds. Health Publications, 2006.

4 Speakman MJ, Kirby RS, Joyce A, Abrams P, Pocock $\mathrm{R}$ : The British Association of Urological Surgeons. Guideline for the primary care management of male lower tract symptoms. BrJ Urol Int 2004;93:9895-90.

5 Abrams P. New words for old: lower urinary tract symptoms for “prostatism.” BMJ 1994;308:929-30.

\section{MENTAL CAPACITY ACT}

\section{Clarification}

Nicholson et al say in their article that, except when a court of protection order-a consequence of which is the deprivation of liberty-is in place, the Mental Capacity Act cannot be used to give care involving deprivation of liberty (see code of practice for details). ${ }^{1}$

This is not necessarily correct, and following this advice may make readers believe that they may not give life saving treatment entailing deprivation of liberty for physical illness to a person without mental capacity and without an existing court order when it is lawful and necessary to do so. Section 6.52 of the code of practice of the Mental Capacity Act 2005 explains the interpretation of "deprivation of liberty" derived from European Court of Human Rights judgments. ${ }^{2}$ Section 50 paragraph (2) of part 2 chapter 2 of the Mental Health Act 2007 amends the Mental Capacity Act 2005 specifically to provide for situations where it is lawful and necessary for deprivation of liberty necessary for life sustaining treatment, ${ }^{3}$ including while a court decision is being sought.

The authors say that the current Mental Health Act (1983) is due to be replaced by a new one (2007) in 2008. The Mental Health Act 2007 will amend rather than replace the Mental Health Act 1983.

Peter Simmons consultant psychiatrist, Queen Elizabeth II Hospital, Welwyn Garden City, Hertfordshire AL7 4HQ PSimmons@doctors.org.uk

Competing interests: None declared

1 Nicholson TRJ, Cutter W, Hotopf M. Assessing mental capacity: the Mental Capacity Act. BMJ 2008;336:322-5. (9 February.)

2 The Mental Capacity Act 2006, code of practice. www. justice.gov.uk/docs/mca-cp.pdf

3 Mental Health Act 2007 www.opsi.gov.uk/ACTS/ acts2007/pdf/ukpga_20070012_en.pdf

\section{How research is affected}

The Mental Capacity Act 2005 could be regarded as protective to both patient and clinician in the circumstances of routine medical care. ${ }^{1}$ It has also helped clarify the issue of capacity when patients are asked to take part in research studies. Sections 30-34 of the act deal very well with issues of

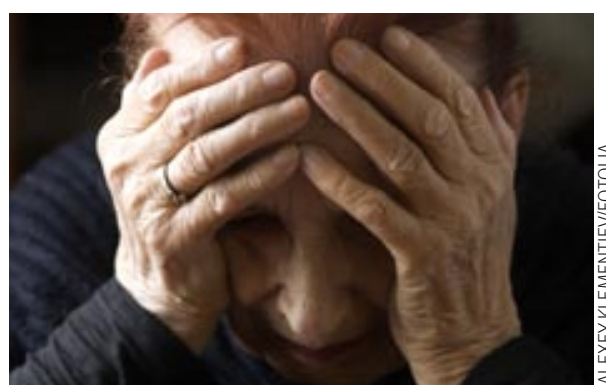

diminished capacity and enrolment to clinical studies. ${ }^{2}$ Far from being too restrictive to those wishing to study groups of patients with diminished capacity, the act is supportive, as long as the patient group being studied must necessarily be recruited at a time when capacity is diminished and time is of the essence-for example, studies in acute myocardial infarction.

Section 31, paragraph 5a, highlights that the research study must have the potential to benefit the patient without imposing on the patient a burden that is disproportionate to the potential benefit to him or her.

For researchers it is important to note that the act does not apply necessarily to trials which fall under the Medicines for Human Use Regulations 2004, as separate legislation and guidance exists.

Researchers must work closely with their local ethics committee to ensure that the consent process is appropriate to the situation, and that the stipulations of the act are followed. It is also important to realise that research in patient groups with diminished capacity is essential in some circumstances and that the Mental Capacity Act 2005 clearly allows for this. Andrew J Ludman cardiology research fellow, Hatter Cardiovascular Institute, University College London, London WC1E 6HX

a.ludman@ucl.ac.uk

Competing interests: None declared.

1 Nicholson TRJ, Cutter W, Hotopf M. Assessing mental capacity: the Mental Capacity Act. BMJ 2008;336:322-5. (9 February.)

2 Department for Constitutional Affairs, United Kingdom. Mental Capacity Act 2005. www.opsi.gov.uk/acts/ acts2005/pt1-pb8-11g30,3. 2008.

\section{USER INVOLVEMENT}

\section{Participatory approach works}

Fudge et al report that users were not involved in defining categories or criteria for their involvement in the stroke programme on which this published ethnography is based. ${ }^{1}$

In our experience, user involvement, and research about user involvement, requires and benefits from a participatory approach. ${ }^{2}$ This fosters congruence between the intentions of the work and the methods used. For our participatory research project we used a peer research model involving refugees and asylum 
seekers in Irish primary care. ${ }^{3}$

Five community representatives were active from the outset in shaping the research aims and objectives, co-designing research materials, doing fieldwork, and co-analysing collected data. The community representatives also defined criteria for evaluating their involvement.

They characterise their involvement as transformative for themselves and the wider community. They describe themselves as mediators and speak of themselves as a link between worlds of the Irish health service and their local networks. They say that they are seen as role models in the community, whose members have been prompted to be proactive about elements of their own health care. They now want to participate in more health related projects.

Anne MacFarlane lecturer in primary care,

Department of General Practice, National University of Ireland, Galway, Republic of Ireland

anne.macfarlane@nuigalway.ie

Mary O’Reilly-de Brún director

Tomas de Brún director, Centre for Participatory Strategies, Clonbur, Galway

Competing interests: The Centre for Participatory

Strategies provides qualitative and participatory research design, training, and support. It has collaborated with the Department of General Practice, NUI, Galway, on participatory research projects.

1 Fudge N, Wolfe CDA, McKevitt C. Assessing the promise of user involvement in health service development ethnographic study. BMJ 2008;336:313-7. (9 February.)

2 Chambers R. Whose reality counts? Putting the first last. London: Intermediate Technology Publications, 1997.

3 MacFarlane A, Pieper HO, Clerkin P, Dzebisova Z, Kanapish D, Kovacevic B, et al. The impact of language as a barrier in general practice: a qualitative study with general practitioners and refugee and asylum seekers. Forum 2007; February:16-7.

\section{PPRS}

\section{Not dead yet}

Claxton et al boldly state that the current Pharmaceutical Price Regulation Scheme (PPRS) is dead. ${ }^{1}$ Would that were so.

The PPRS is rooted in the past and fails both to deliver its stated objectives and to reflect the realities of the modern NHS and the modern pharmaceutical industry. When I was head of the PPRS branch in the Department of Health 15 years ago I argued that with the introduction of prescribing budgets the scheme was no longer necessary or appropriate. With practice based commissioning the case for fundamental reform is now unanswerable.

The government plans to consult shortly on likely changes to the scheme, and to implement those changes by July. What the consultation document will say remains confidential, but all the indications are that the focus will be on a quick fix now (consisting of a mandatory price cut accompanied by cosmetic changes) coupled with a promise to consider the proposed value based pricing over the next two (or three, or five) years. Another opportunity missed.

Jim Furniss consultant, Bridgehead International, Pera Innovation Park, Melton Mowbray, Leicestershire LE13 OPB jim.furniss@bridgehead.com

Competing interests: None declared.

1 Claxton K, Briggs A, Buxton MJ, Culyer AJ, McCabe C, Walker S, et al. Value based pricing for NHS drugs: an opportunity not to be missed? BMJ 2008;336:251-4. (2 February.)

\section{STRATEGIES FOR STATINS}

\section{The CASE for fire and forget}

I write with reference to the editorial by DonnerBanzhoff and Sönnichsen. ${ }^{1}$ Four factors make the CASE for Shepherd's original proposal to move the prescription of statin on to the same footing that aspirin now occupies. ${ }^{2}$

Cost-A diminishing returns dose-response curve exists, whereby the initial $10 \mathrm{mg}$ of simvastatin produces $75 \%$ of the maximum response, and each dose increment produces a reducing incremental gain, at increasing cost per unit gain. For example, since $10 \mathrm{mg}$ of atorvastatin produces half the cholesterol lowering achieved by $80 \mathrm{mg}$ atorvastatin, and drugpricing is effectively linear, then offering eight people $10 \mathrm{mg}$ of atorvastatin is four times as effective as offering one person $80 \mathrm{mg}$. Atorvastatin is 20 times more costly than simvastatin, but only twice as potent, dose for dose

Acceptability-Avoidance of unnecessary repeated cholesterol tests and clinic visits is welcomed by patients, doctors, and health accountants

Safety-The risk of side effects increases with dosage

Effectiveness-All patients at cardiovascular risk benefit from statin treatment, regardless of their initial cholesterol level.

The benefits to the nation of generically priced simvastatin are 20 times that of the patent price atorvastatin. The higher the cardiovascular risk the greater the gain, regardless of cholesterol. A threshold of risk exists (currently a 10 year cardiovascular risk $>20 \%$ ), above which the balance of harm is outweighed by the benefit of $10 \mathrm{mg}$ simvastatin, providing the greatest good to the greatest number, at an affordable cost to the nation.

Who needs polypills and polyclinics? Your local pharmacist now offers a simvastatin and an aspirin a day, to keep the doctor away. L Sam Lewis general practitioner, Surgery, Newport, Pembrokeshire SA42 OTJ

sam@garthnewydd.freeserve.co.uk

Competing interests: None declared.

1 Donner-Banzhoff N, Sönnichsen A. Strategies for prescribing statins. BMJ 2008;336:288-9. (9 February.)

2 Shepherd J. Resource management in prevention of coronary heart disease: optimising prescription of lipidlowering drugs. Lancet 2002;359:2271-3.

\section{Treat to target benefits no one}

Donner-Banzhoff and Sönnichsen highlight the lack of evidence for "treating to target" with statins. ${ }^{1}$ Treatment targets can lead to an escalation of treatment that is not evidence based, drain clinical resources through repeat clinic visits and blood tests, and can lead to the unnecessary use of branded statins, which bring no additional benefits and are at least 13 times more expensive than generic statins. ${ }^{2}$

However, they have oversimplified the Scottish Intercollegiate Guidelines Network (SIGN) advice on statins. The SIGN guideline differs from other guidance in the United Kingdom: it does not recommend treatment targets for statins in primary prevention of cardiovascular disease. ${ }^{3}$ It uses the findings of Hayward's exploration of statin treatment targets ${ }^{4}$ to note that current clinical evidence does not show that lipid treatment should be titrated to achieve proposed low density lipoprotein (LDL) cholesterol targets. The only treatment target mentioned in the SIGN guideline relates to secondary prevention of cardiovascular disease, and this seems to have been a compromise in response to the targets set in the quality and outcomes framework (QOF). Accordingly, the QOF should move away from setting treatment targets for statins. One alternative would be a QOF target for compliance with statin treatment.

D Graham Mackenzie consultant in public health medicine gm@nhs.net

Philip Rutledge consultant in medicines management, NHS Lothian, Edinburgh EH8 9RS

Competing interests: None declared.

1 Donner-Banzhoff N, Sönnichsen A. Strategies for prescribing statins. Evidence supports prescribing a standard dose without further testing or dose adjustment. BMJ 2008;336:288-9. (9 February.)

2 Scottish drug tariff. February 2008. www.isdscotland. org/isd/2246.html

3 Risk estimation and the prevention of cardiovascular disease. A national clinical guideline. Scottish Intercollegiate Guidelines Network 2007. SIGN 97.

4 Hayward RA, Hofer TP, Vijan S. Lack of evidence for recommended low-density lipoprotein treatment targets: a solvable problem. Ann Intern Med 2006;145:520-30.

\section{MEDICAL STUDENTS’ SEX LIVES}

\section{A snippet is not enough}

What an extraordinary "In brief." "Medical students report poor sex lives: Many medical students are dissatisfied with their sex lives, a survey at the University of California at San Francisco has found": compared with whom? Students of history? Sellers of Big Macs?

The link didn't work [it should, Ed], so it must remain a mystery.

Neville W Goodman retired anaesthetist, Bristol BS9 3LW nevwgoodman@mac.com

Competing interests: None declared.

1 In brief. Medical students report poor sex lives. BMJ 2008;336:240. (2 February.) 